\title{
The handling and fate of spermatophores in Neoentobdella diadema and $N$. apiocolpos (Monogenea: Capsalidae: Entobdellinae)
}

\author{
Graham C. Kearn $^{1}$, Ian D. Whittington ${ }^{2,3}$ and Louis Euzet ${ }^{4}$ \\ ${ }^{1}$ School of Biological Sciences, University of East Anglia, Norwich, Norfolk NR4 7TJ, UK; \\ ${ }^{2}$ Monogenean Research Laboratory, Parasitology Section, The South Australian Museum, North Terrace, Adelaide, South \\ Australia 5000, Australia; \\ ${ }^{3}$ Marine Parasitology Laboratory, School of Earth and Environmental Sciences (DP418), The University of Adelaide, North \\ Terrace, Adelaide, South Australia 5005, Australia; \\ ${ }^{4}$ Université Montpellier 2, Station Méditerranéenne de l’Environnement Littoral, 1 Quai de la Daurade, 34200 Sète, France
}

Key words: Monogenea, Entobdellinae, Neoentobdella diadema, Neoentobdella apiocolpos, Entobdella soleae, spermatophores

\begin{abstract}
The elongated encased spermatophores of the capsalid (entobdelline) monogeneans Neoentobdella diadema (Monticelli, 1902) Kearn et Whittington, 2005 and N. apiocolpos (Euzet et Maillard, 1967) Kearn et Whittington, 2005 have been found attached by their proximal ends to the region of the vaginal opening, with the bulk of the spermatophore projecting from the vagina and therefore lying outside the body. In spite of previous reports, no spermatophores were found projecting from the common genital opening and if spermatophore exchange is as rapid as it is in the related entobdelline Entobdella soleae, then the chances of finding a spermatophore in this location are small. In $N$. diadema and $N$. apiocolpos it is likely that sperm enters the vagina through the open proximal end of an attached spermatophore, after which the empty spermatophore case is probably discarded. There is no evidence for a previous proposal that the whole spermatophore is engulfed by the vagina followed by digestion of the case to release the sperm. Three specimens of $N$. diadema were found each with two spermatophore cases projecting from the vagina and a specimen of $N$. apiocolpos carried three cases. Assuming that each parasite is able to donate or receive only one spermatophore at each mating, then the presence of one spermatophore does not prevent a further mating and acceptance of a fresh spermatophore. In spite of differences between the spermatophores of E. soleae and N. diadema/N. apiocolpos, the events of spermatophore exchange may be similar.
\end{abstract}

In Entobdella soleae (Van Beneden et Hesse, 1864) Johnston, 1929, a capsalid monogenean parasite (Entobdellinae) of the skin of the common sole Solea solea (L.) (Soleidae), mutual cross insemination occurs by exchange of soft, jelly-like spermatophores, which are implanted externally on the ventral body surface in the region of the vaginal opening (Kearn 1970). Sperm from the central region of the spermatophore is drawn into the vagina by contractions of the body and the remaining "jelly" is eventually discarded. Spermatophores have also been reported in two other entobdelline monogeneans from the skin of stingray hosts, namely in Neoentobdella diadema (Monticelli, 1902) Kearn et Whittington, 2005 by Llewellyn and Euzet (1964, as Entobdella diadema Monticelli, 1902) and in N. apiocolpos (Euzet et Maillard, 1967) Kearn et Whittington, 2005 by Euzet and Maillard (1967, as Entobdella apiocolpos Euzet et Maillard, 1967). However, exchange of spermatophores has not been observed in living specimens of these parasites. The spindle-shaped spermatophores of $N$. diadema differ from those of $E$. soleae in possessing a thin outer case (see Llewellyn and Euzet 1964, as Entobdella diadema) and Kearn and Whitting- ton (2005) found that the spermatophores of N. apiocolpos were similarly encased. The common genital aperture in N. diadema is provided with a pair of muscular lips and in a line drawing by Llewellyn and Euzet (1964, text-fig. 1, as Entobdella diadema), these lips are shown grasping the end of a spermatophore, the rest of which projects freely from the left side of the body. Llewellyn and Euzet claimed to have found several specimens in which spermatophores were retained in this way by the genital lips. However, in a photomicrograph by the same authors of a parasite with a projecting spermatophore (Llewellyn and Euzet 1964, plate 1, fig. 1), the proximal end of the spermatophore appears to be lodged in the vagina and not grasped by the genital lips, in spite of the statement in the legend that the figure shows "a spermatophore held in the genital opening". Llewellyn and Euzet made no mention of spermatophores projecting from the vagina. This inconsistency and the finding by one of us (GK) of a specimen of N. diadema with a spermatophore projecting from the vagina (Kearn 2004, fig. 3.17), prompted a reassessment of the way in which these encased spermatophores are handled. 


\section{MATERIALS AND METHODS}

In May 1973 the opportunity arose to collect specimens of Entobdella diadema (transferred to Neoentobdella by Kearn and Whittington 2005) from the skin of a heavily infected stingray, Dasyatis pastinaca (L.), in the Aquarium of the Marine Biological Association of the United Kingdom at Plymouth, England. A sample of 33 of these parasites was stained in Ehrlich's haematoxylin and each parasite was mounted on a microscope slide in Canada balsam. In addition, 14 preserved slide-mounted specimens of Neoentobdella apiocolpos from the skin of the stingray Taeniura grabata (Geoffroy SaintHilaire) were examined. These included 6 specimens collected in July 1951 from Gorée, Senegal and 8 specimens on 5 slides collected in June 1996 from Tunisia. All of these mounted specimens were searched for the presence of attached spermatophores and when found, their shapes and precise location were determined and their contents examined using phase contrast optics.

\section{RESULTS}

In $N$. diadema the vaginal opening and the common genital opening lie close together on the left margin of the body, with the vaginal opening anterior to the genital opening (Fig. 1; see also Llewellyn and Euzet 1964, as Entobdella diadema). In our sample of 33 stained adult specimens of $N$. diadema, 13 individuals were found to be carrying spermatophores. In spite of the proximity of the vaginal and common genital openings, it was possible to see that in all of these 13 individuals, the proximal end of each spermatophore was lodged in the vaginal opening (e.g. Figs. 2-4). No individuals were found with a spermatophore grasped by the genital lips. Three individuals each carried two spermatophores, both of which projected from the vagina (e.g. Fig. 5).

Each attached spermatophore of $N$. diadema was sausage-shaped, with a tapering free (distal) end (Figs. 35). The opposite (proximal) end of each spermatophore was truncated or rounded where it was lodged apparently just inside the vaginal opening, and this terminal region of the spermatophore often had an affinity for Ehrlich's haematoxylin. The proximal ends of some of the spermatophores appeared to be open and in a few individuals, staining was concentrated in all or part of the rim of each circular aperture, creating a stained ring or partial ring (Figs. 4, 5). The spermatophores of $N$. diadema are variable in size (compare Figs. 3, 4 and 5). The dimensions of a sample of 10 attached spermatophores were as follows: total length $712(513-869) \mu \mathrm{m}$; breadth at the widest region $121(100-175) \mu \mathrm{m}$. Since these parasites had been flattened before preservation, these dimensions may be greater than in the living, unflattened animal. The lengths and widths of presumably unflattened spermatophores recorded by Llewellyn and Euzet (1964) were about $600 \mu \mathrm{m}$ and $150 \mu \mathrm{m}$ respectively (sample size not given).

In Neoentobdella apiocolpos the common genital aperture and the vaginal opening are widely separated, the genital aperture being located on the left body margin and the vaginal opening on the ventral surface some distance posteromedially from the genital aperture (Fig. 6, see also Euzet and Maillard 1967, as Entobdella apiocolpos). Euzet and Maillard referred to the presence of spermatophores in this parasite species but did not illustrate them. Two out of the 14 specimens of $N$. apiocolpos examined by us were found to carry spermatophores. One individual carried a single spermatophore and the other individual carried three spermatophores (Fig. 7). Like those of $N$. diadema, the spermatophores of $N$. apiocolpos possess a thin wall, but are a little smaller with a truncated rather than tapering distal end and a relatively narrow proximal end. The average length of the 4 spermatophores of $N$. apiocolpos was 467 (376-535) $\mu \mathrm{m}$ and the maximum width was about $80 \mu \mathrm{m}$. The proximal ends of all of these spermatophores were lodged in the vagina and not in the common genital aperture (Fig. 7).

Some of the attached spermatophores of $N$. diadema were full of material (sperm?) (e.g. Fig. 2), but others had little or no contents (Figs 4, 5). The four attached spermatophores of $N$. apiocolpos contained varying amounts of material that is likely to be sperm, but it proved difficult to confirm this supposition.

\section{DISCUSSION}

Llewellyn and Euzet (1964) claimed to have seen the genital lips of several specimens of Neoentobdella diadema (as Entobdella diadema) grasping the proximal end of a spermatophore and suggested that these lips are used to manoeuvre the spermatophore into the vagina of a mating partner. However, all of the attached spermatophores of $E$. diadema observed by us (13 out of 33 adult parasites in our collection carried spermatophores) were found to be projecting from the vagina and not from the common genital opening where the genital lips are located. Similarly, 2 out of 14 specimens of $N$. apiocolpos were found to be carrying spermatophores and all of these were projecting from the vaginal opening.

Since the parasites that we examined had been detached from the host prior to preservation and mounting, it could be argued that the positions of the spermatophores attached to these specimens were abnormal. However, experience with other capsalids, for example $E n$ tobdella soleae, Benedenia seriolae, and B. rohdei (as Benedenia sp. 1) (see Kearn 1970, 1992 and Kearn and Whittington 1992, respectively), indicates that parasites separated from the host and maintained in vitro continue to mate normally. In fact, adults of E. soleae remain attached in vitro for many hours, during which time they lay viable eggs (Kearn 2002) and even attempt to feed as well as exchange spermatophores (Kearn 1970). Moreover, many of the spermatophores projecting from the vaginal openings in our mounted specimens of $N$. diadema and $N$. apiocolpos appeared to contain little or no sperm, a condition consistent with expected normal function. 

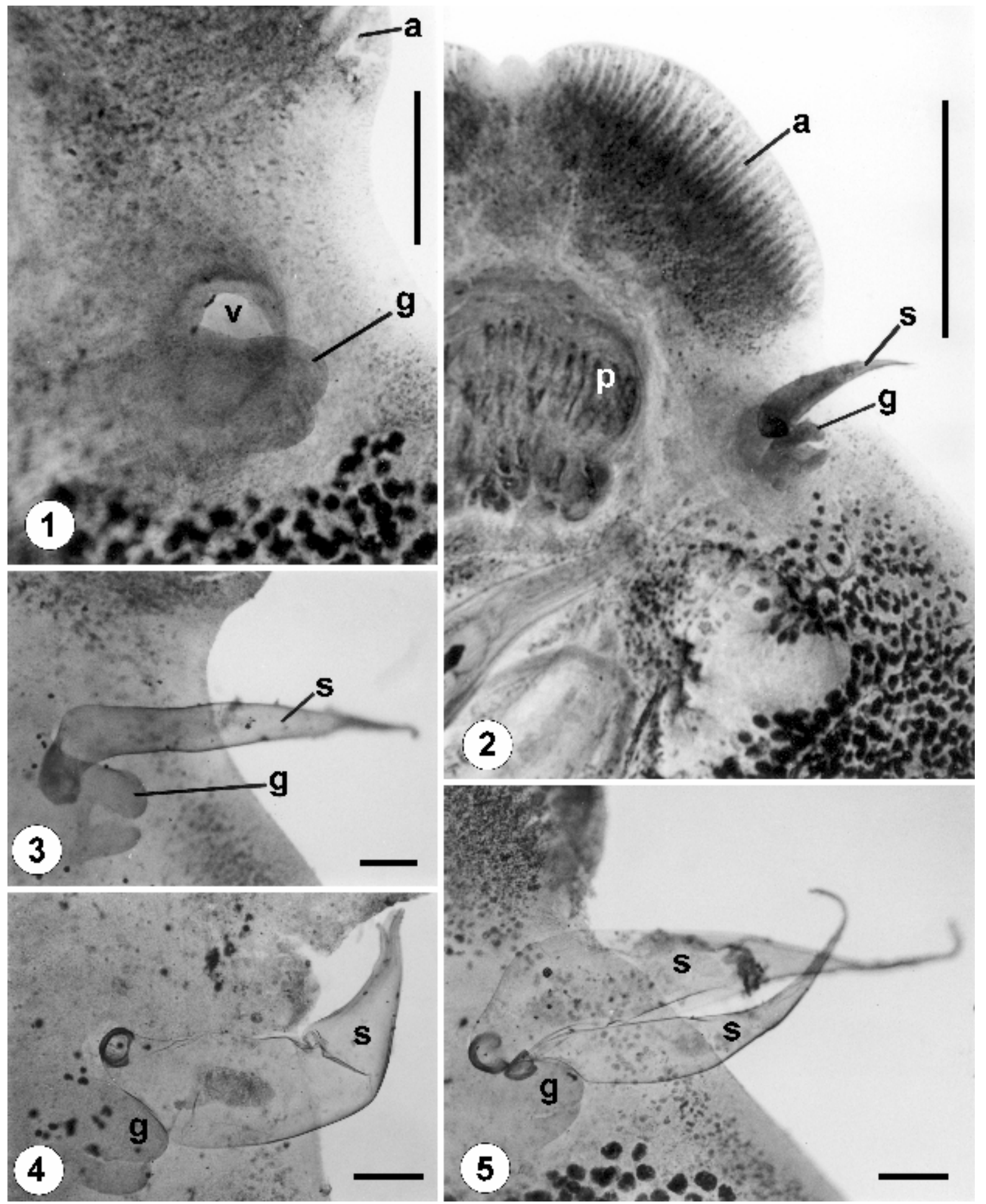

Figs. 1-5. Neoentobdella diadema. Reproductive openings and spermatophores. Fig. 1. Opening of the vagina (v) and adjacent genital lips (g). No spermatophore present. Fig. 2. Ventral view of the anterolateral region of the body (left side) showing an attached spermatophore (s) and the genital lips (g). Figs. 3-5. Enlarged region of the reproductive openings in three different individuals with attached spermatophores (s). Note genital lips (g). a - adhesive pad; p - pharynx. Scale bars: Fig. $1=250 \mu \mathrm{m}$; Fig. $2=1 \mathrm{~mm}$; Figs. $3-5=100 \mu \mathrm{m}$. 
Our failure to find any parasites with spermatophores projecting from the common genital opening may reflect the fact that a donor parasite proffers the spermatophore for an extremely brief period of time, so that the chances of finding a parasite with a spermatophore in this location are small. Llewellyn and Euzet (1964) may have been fortunate to witness this brief event in $N$. diadema (as Entobdella diadema), although, as their plate 1 , fig. 1 shows, they were mistaken on at least one occasion about the location of a spermatophore. Such a mistake would be easy to make because the vaginal opening and the genital lips in this parasite species are close together. The presence of anatomical structures capable of grasping the end of a freshly extruded spermatophore, i.e. genital lips in N. diadema and a genital sphincter in $N$. apiocolpos (see Euzet and Maillard 1967, as Entobdella apiocolpos), is consistent with presentation of spermatophores by donor parasites in the manner described by Llewellyn and Euzet. However, if this were the case it would be expected that an individual with a spermatophore to offer would hold the spermatophore by its elongated tapering $(=$ distal) end rather than by the opposite truncated (= proximal) end as shown by Llewellyn and Euzet in their text-fig. 1.

Llewellyn and Euzet (1964) also suggested that the muscular/glandular vestibule at the distal end of the vagina of $N$. diadema (as Entobdella diadema) serves as a receptacle where the wall of the spermatophore is digested, liberating the sperm. However, we found evidence that no more than the proximal end of a spermatophore enters the vagina. We also observed that some of the attached spermatophores of $N$. diadema retained little contents, suggesting that sperm is withdrawn into the vagina while the bulk of the spermatophore lies outside the animal. However, the observation that the proximal end of the spermatophore appears to be open and that this region of the spermatophore, and sometimes the rim of the aperture, have an affinity for haematoxylin, may be a manifestation of the erosion of the proximal end of the spermatophore case by digestive secretion from the vagina, as proposed by Llewellyn and Euzet (1964). On the other hand, the staining may reveal the presence of adhesive material serving to attach the spermatophore to the vagina. Attachment of the spermatophore to the parasite is sufficiently strong to resist the stresses and strains of flattening, preservation and processing, but the mechanism of attachment remains to be determined. Whatever it is, the bond or grip is eventually weakened after sperm assimilation by the vagina and the empty spermatophore case is presumably released.

In conclusion, the evidence we have presented suggests that during mating in $N$. diadema and N. apiocolpos spermatophores are not engulfed and then digested by the vagina of a recipient, but are held in place only by their proximal ends at, or within, the vaginal opening. After transfer of the sperm load from the spermato- phore to the vagina (possibly by suction), the empty spermatophore case is presumably discarded. If this interpretation of events turns out to be correct, then sperm exchange in $N$. diadema and in $N$. apiocolpos may not be significantly different from that of $E$. soleae. Furthermore, if transfer of spermatophores in $N$. diadema and $N$. apiocolpos is as rapid as it is in E. soleae (no more than a few seconds duration, see Kearn 2004, p. 46), then spermatophores may be transferred to the vagina of a co-copulant as soon as they are extruded and specimens of $N$. diadema and $N$. apiocolpos with newly assembled spermatophores projecting from the common genital opening are unlikely to be found. Confirmation or otherwise of these proposed events must wait until spermatophore exchange is witnessed in living parasites.

It is noteworthy that some individuals of $N$. diadema and $N$. apiocolpos have more than one spermatophore projecting from the vaginal opening. Each of three individuals of $N$. diadema carried two spermatophores and one individual of $N$. apiocolpos carried three spermatophores. It is possible that more than one spermatophore is transferred in the course of a single mating, but this would require the parasite to have sufficient spermatophore casing material and spermatozoa available to assemble two or three spermatophores in rapid succession. In Entobdella soleae, where spermatophore exchange has been observed frequently, production of a single spermatophore leads to a significant reduction of stored spermatophore matrix material (G. Kearn, unpublished observation). Therefore it seems unlikely that $E$. soleae would have enough material to assemble a second spermatophore immediately after the first, and transfer of two spermatophores during a single mating has not been recorded. The question of whether or not Neoentobdella diadema and $N$. apiocolpos are capable of donating/receiving multiple spermatophores at a single mating can only be resolved when the opportunity arises to observe spermatophore exchange in living parasites.

If the assumption is made that Neoentobdella diadema and $N$. apiocolpos are not capable of donating or receiving more than one spermatophore during a single mating, then their spermatophore cases are not immediately discarded after delivery of their sperm content. It also means that the presence of a spermatophore attached to the vaginal opening does not preclude the acceptance of another. It might be considered advantageous for a donor parasite during mating to dislodge an attached spermatophore from a previous donor, but there would be no advantage if the first spermatophore had already delivered its load of sperm.

After sperm delivery, some individuals of Entobdella soleae retain the spermatophore matrix ("jelly") for at least a few minutes and possibly longer (this duration has not been measured), but there is no evidence that a second spermatophore can be accepted before the first is discarded. This may mean that E. soleae is unable to 

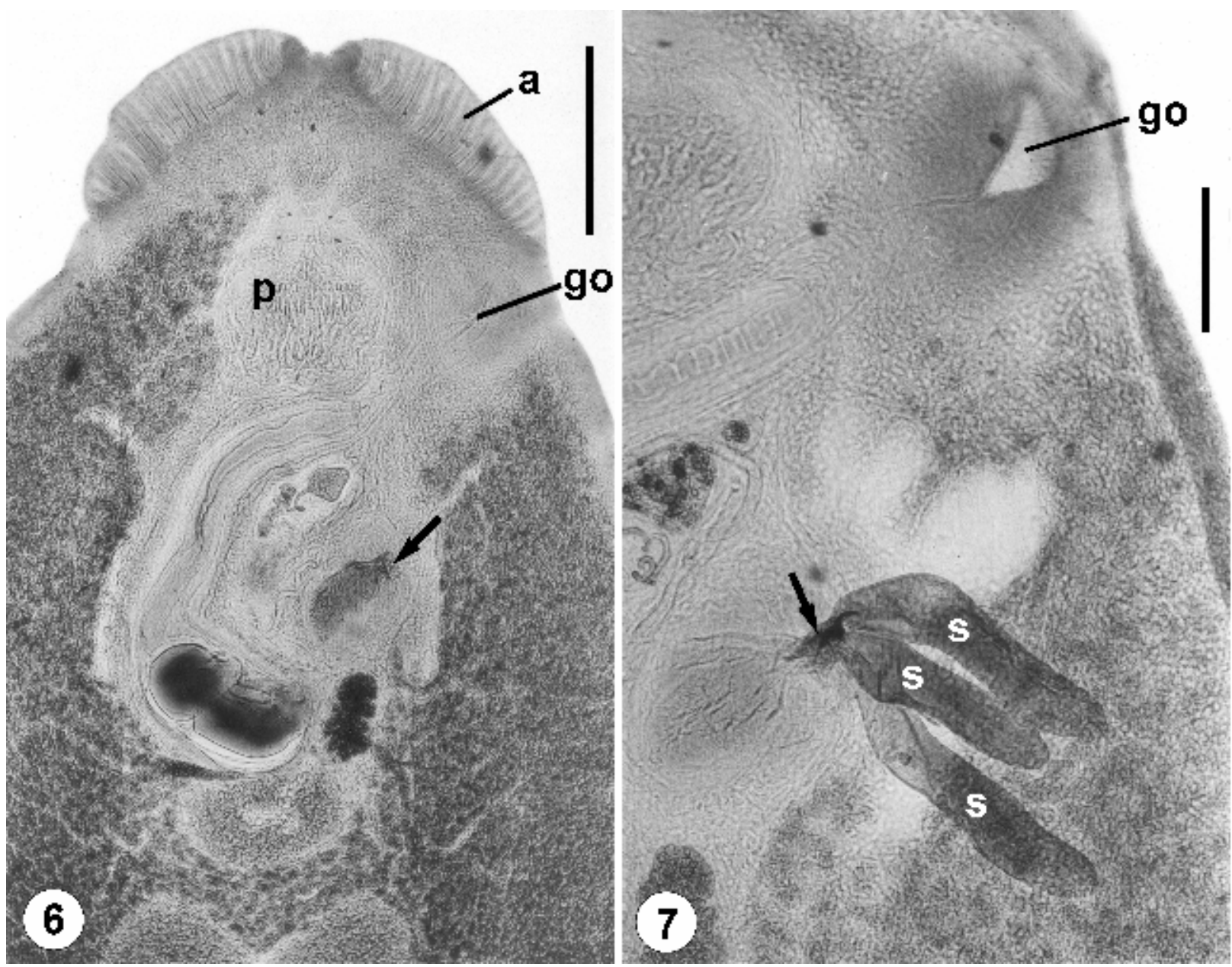

Figs. 6, 7. Neoentobdella apiocolpos. Fig. 6. Ventral view of the anterior region of the body showing the positions of the vaginal opening (arrow) and the common genital opening (go). Fig. 7. Enlarged view of the anterolateral region of the body (left side) showing three spermatophores (s) with their proximal ends (arrow) attached within the vaginal opening. Note genital opening (go). a - adhesive pad; p - pharynx. Scale bars: Fig. $6=500 \mu \mathrm{m}$; Fig. $7=250 \mu \mathrm{m}$.

mate as frequently as $N$. diadema and $N$. apiocolpos, and this may be offset in E. soleae by special provision for storage of sperm. Entobdella soleae retains sperm in a convoluted and voluminous proximal region of the vagina and in seminal receptacles (see Kearn 1985), while comparable storage facilities are not present in Neoentobdella diadema and N. apiocolpos (see Llewellyn and Euzet 1964 as Entobdella diadema and Euzet and Maillard 1967 as E. apiocolpos, respectively). Thus, the relationship between frequency of insemination, volume of sperm transferred and provision of storage facilities may well be different in Entobdella and Neoentobdella.

Another factor that is important in consideration of the reproductive biology of entobdellines is whether or not self insemination takes place. This phenomenon has been identified by Kearn and Whittington (1992) in species of Benedeniella (thought to be an entobdelline; Whittington, work in progress), where it is achieved by deflection of the cirrus into the uterus before the female reproductive system becomes active. The absence of a vagina in Neobenedenia spp. (see Whittington and Horton 1996) means that the only entry route for sperms is via the uterus. Whittington and Horton (1996) found a specimen of $N$. melleni with the penis directed into its own uterus, but it is not known whether cross insemination takes place in Neobenedenia spp. An experimental study by Kearn et al. (1993) found no evidence for self insemination in $E$. soleae and self insemination has not been observed during many hours of observation of living parasites (Kearn et al. 1993), but the finding of an immature specimen of Neoentobdella natans in which the penis was deflected into the uterus (Kearn and Whittington 2005), raises the possibility that self insemination via the uterus may occur in Neoentobdella. In addition, the close proximity of the openings of the vagina and the common genital duct in $N$. diadema (e.g. see Fig. 1) would seem to permit the opportunity for self insemination via the vaginal route, but in $N$. apiocolpos considerable body contortion would be required to achieve this. 
Spermatophores have not yet been identified with certainty in other species of Neoentobdella. Bodies with a jelly-like consistency were observed associated with $N$. natans (see Kearn and Whittington 2005) but their status as spermatophores needs confirmation.

Insemination by way of spermatophores is not universal among capsalid monogeneans. In addition to the instances noted above where self insemination may occur in juveniles by insertion of the penis or cirrus in the uterus of the same individual, mutual sperm exchange seems to be regularly achieved in adults of the benedeniine Benedenia seriolae not by spermatophore exchange but by penile intromission and deposition of sperm directly into the vagina (Kearn 1992). A similar mating behaviour involving intromission was observed in Benedenia rohdei (as Benedenia sp. 1) by Kearn and Whittington (1992). Why some capsalids opt for spermatophore exchange while others that are not so distantly related indulge in mutual copulation by intromission is a fundamental question that has not yet been answered.

Spermatophores have been reported in other monogeneans, e.g. in the gill parasitic diplectanid Diplectanum aequans by Paling (1966), but these reports are rare, possibly because few parasitologists study live parasites.

Acknowledgements. This study was supported in part by Australian Research Council grant no. DP0556780 (20052007) awarded to IDW and Steve Donnellan.

\section{REFERENCES}

EUZET L., MAILLARD C. 1967: Parasites de poissons de mer ouest-africains, récoltés par J. Cadenat. VI. Monogènes de Sélaciens. Bull. Inst. Fondam. Afr. Noire 29: 1435-1493.

KEARN G.C. 1970: The production, transfer and assimilation of spermatophores by Entobdella soleae, a monogenean skin parasite of the common sole. Parasitology 60: 301311.

KEARN G.C. 1985: Observations on egg production in the monogenean Entobdella soleae. Int. J. Parasitol. 15: 187194.

KEARN G.C. 1992: Mating in the capsalid monogenean Benedenia seriolae, a skin parasite of the yellowtail, $\mathrm{Se}$ riola quinqueradiata in Japan. Publ. Seto Mar. Biol. Lab. 35: 273-280.

KEARN G.C. 2002: Entobdella soleae - pointers to the future. Int. J. Parasitol. 32: 367-372.

KEARN G.C. 2004: Leeches, Lice and Lampreys. A Natural History of Skin and Gill Parasites of Fishes. Springer, Dordrecht, The Netherlands, $432 \mathrm{pp}$.

KEARN G.C., JAMES R., EVANS-GOWING R. 1993: Insemination and population density in Entobdella soleae, a monogenean skin parasite of the common sole, Solea solea. Int. J. Parasitol. 23: 891-899.
KEARN G.C., WHITTINGTON I.D. 1992: Diversity of reproductive behaviour in platyhelminth parasites: insemination in some benedeniine (capsalid) monogeneans. Parasitology 104: 489-496.

KEARN G.C., WHITTINGTON I.D. 2005: Neoentobdella gen. nov. for species of Entobdella Blainville in Lamarck, 1818 (Monogenea, Capsalidae, Entobdellinae) from stingray hosts, with descriptions of two new species. Acta Parasitol. 50: 32-48.

LLEWELLYN J., EUZET L. 1964: Spermatophores in the monogenean Entobdella diadema Monticelli from the skin of sting-rays, with a note on the taxonomy of the parasite. Parasitology 54: 337-344.

PALING J.E. 1966: The functional morphology of the genitalia of the spermatophore-producing monogenean parasite Diplectanum aequans (Wagener) Diesing, with a note on the copulation of the parasite. Parasitology 56: 367-383.

WHITTINGTON I.D., HORTON M.A. 1996: A revision of Neobenedenia Yamaguti, 1963 (Monogenea: Capsalidae) including a redescription of $N$. melleni (MacCallum, 1927) Yamaguti, 1963. J. Nat. Hist. 30: 1113-1156. 